\title{
KULEUVEN
}

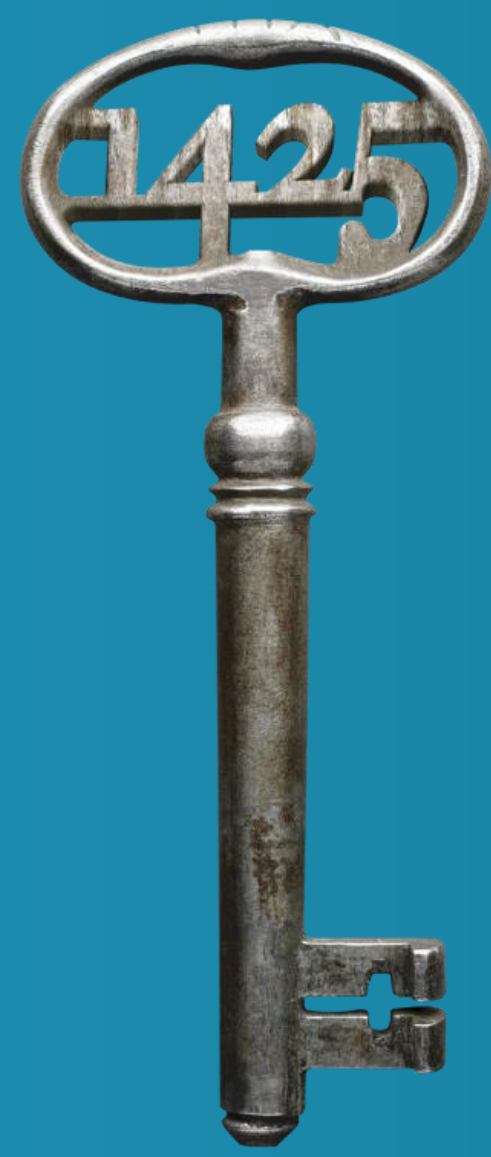

\section{The effect of amylolytic activity and substrate availability on sugar release in non-yeasted dough}

NORE StRuyf, Bianca LefEVERE, KeVIN J. VerstREPEN AND CHRISTOPHE M. COURTIN

14 $4^{\text {th }}$ EYCSTW, Copenhagen, April 162015 


\section{Introduction}




\section{Bread ingredients}

The four main ingredients of bread dough are:

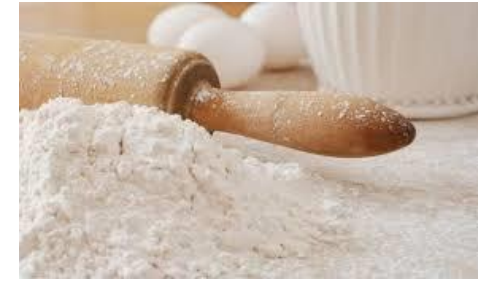

Wheat flour

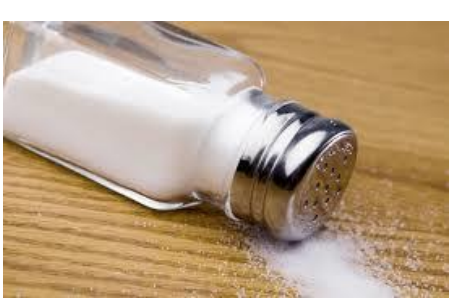

Salt

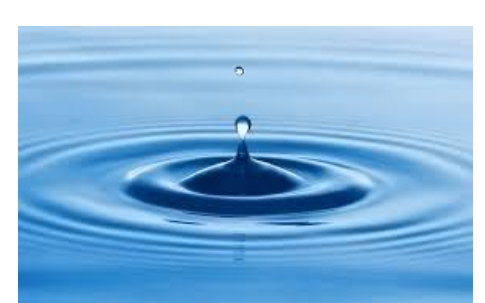

Water

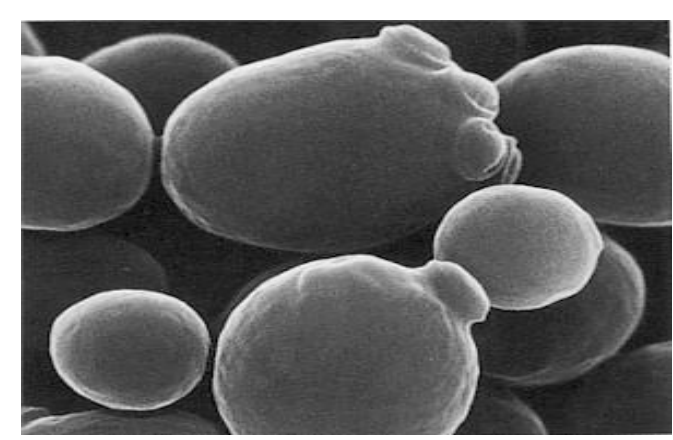

Yeast

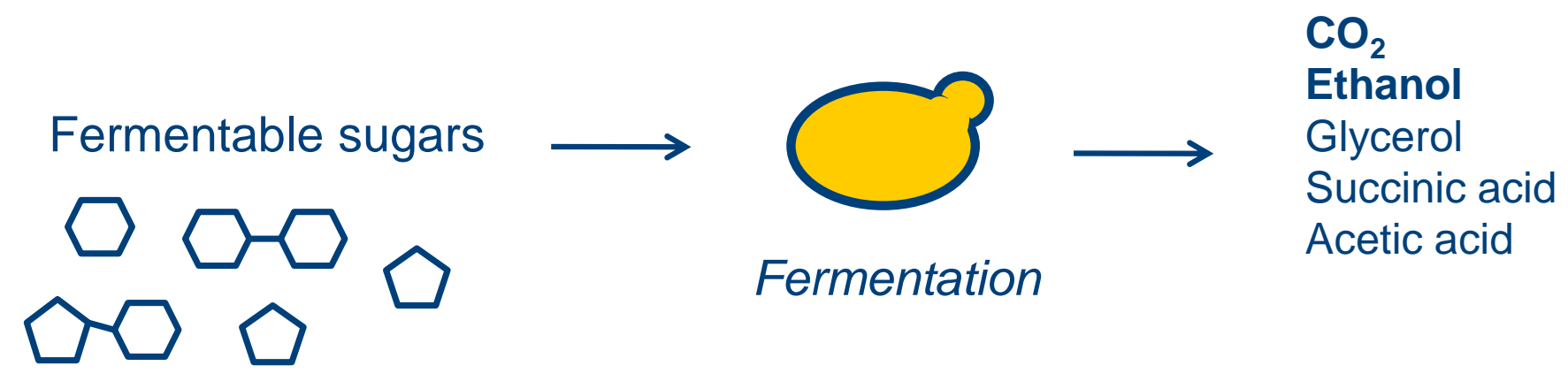




\section{Fermentable sugars in dough}

Different sources of fermentable sugars in dough:

$\longrightarrow \alpha$-Amylase

* Damaged starch: 5-8\%

* Fructan: 1-3\%

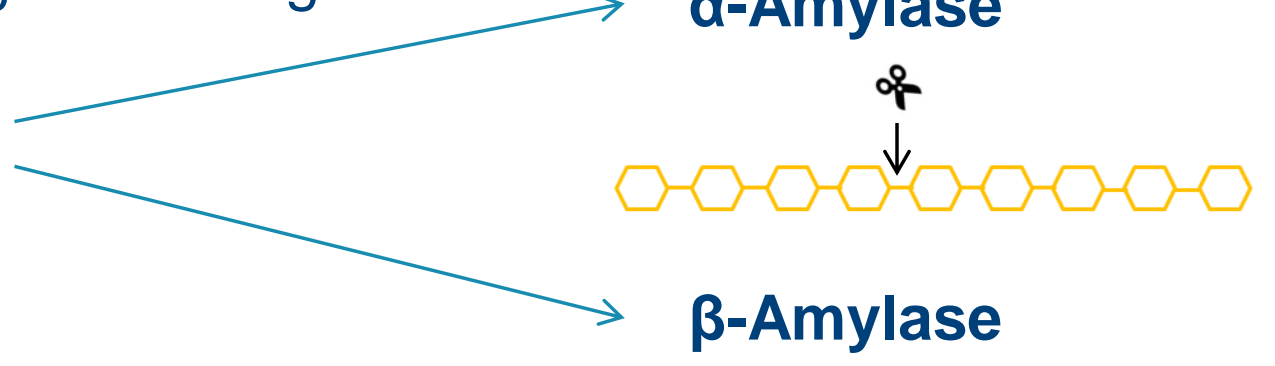

* Free sugars: glucose fructose sucrose $<1 \%$ maltose 


\section{Introduction \\ Research question}

\section{Literature:}

* a-Amylase the limiting factor for sugar release, $\beta$-amylase is present in adequate levels (Drapron and Godon, 1987; Martínez-Anaya et al., 1996; Cauvain and Young, 2007)

* a-Amylase is added to wheat flour at the miller to increase the level of fermentable sugars till a Hagberg falling number of \pm 300 seconds is reached (Hebeda and Zobel 1996; Goesaert et al., 2005; Cauvain and Young, 2007)

\section{What are the limiting factors for sugar release in dough?}

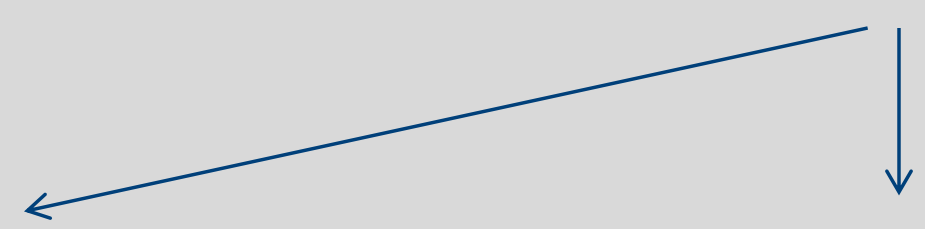

a-Amylase
$\beta$-Amylase

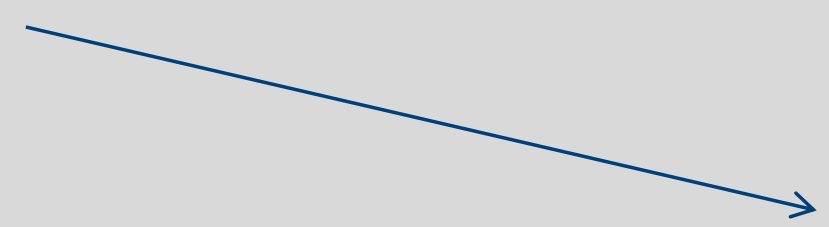

Substrate availability 


\section{Approach}




\section{Approach}

Two different flour types with different amylolytic background

\section{Bilux}

* Low a-amylase activity

* High HFN

* High amount of damaged starch

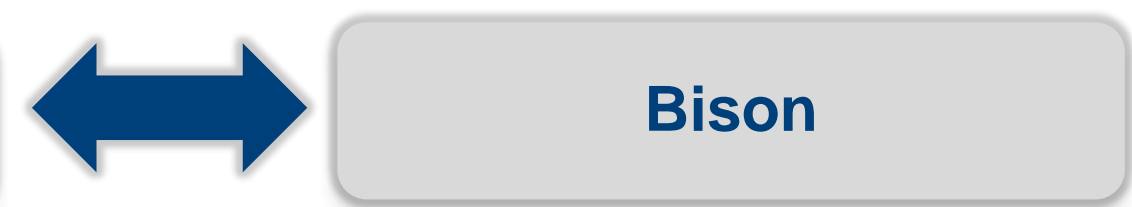

* Higher a-amylase activity

* Lower HFN

* Lower amount of damaged starch 


\section{Approach}

Step 1: Comparison of sugar release in dough samples prepared of Bilux and Bison flour

Step 2: Analysis of sugar release in dough samples prepared from Bilux flour (lowest $\alpha$ amylase activity) with additional enzymes/substrate
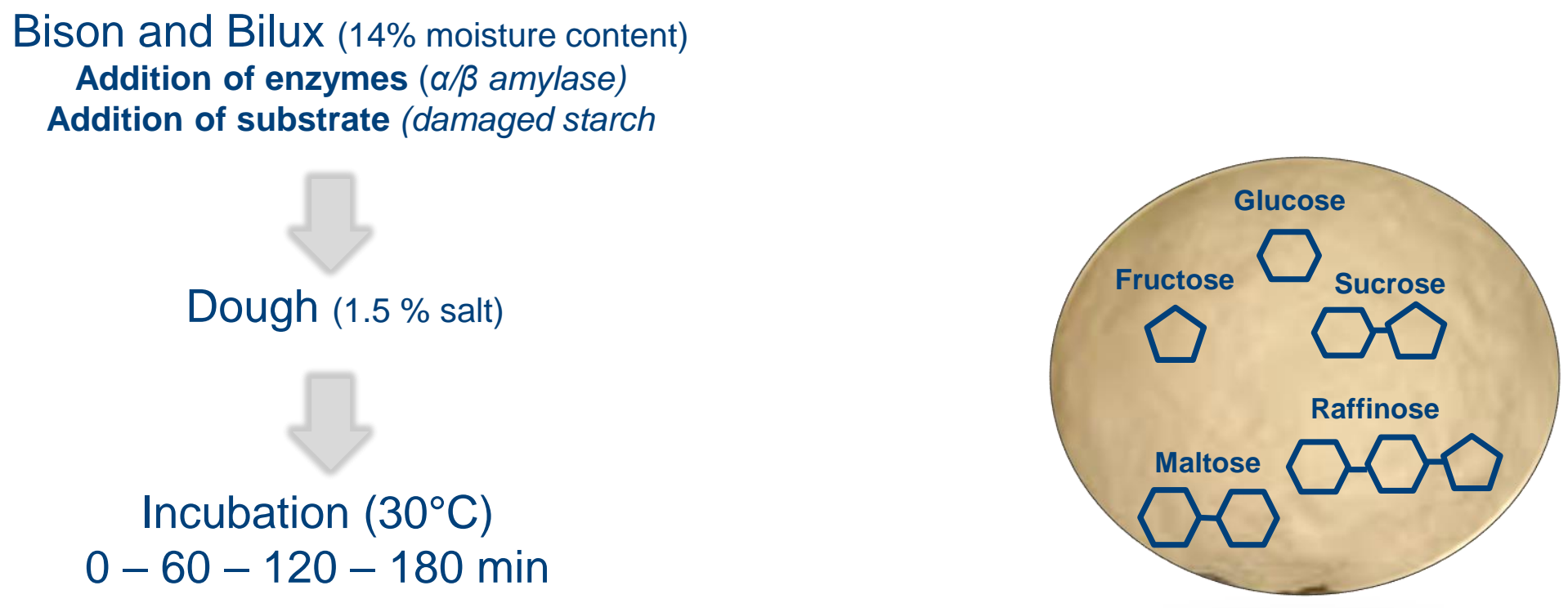

Sugar analysis

High Performance Anion Exchange chromatography (HPAEC) 


\section{Results and conslusions}




\section{Results \\ Flour characterization}

2 different flour types with different amylolytic background

\begin{tabular}{|c|c|c|}
\hline & Bilux & Bison \\
\hline$H F N(s)$ & $477 \pm 18$ & $332 \pm 8$ \\
\hline $\begin{array}{l}\alpha \text {-Amylase activity (Amylazyme Units }\left(\Delta A_{590} / g\right. \\
\text { dm.h)) }\end{array}$ & $1.97 \pm 0.1$ & $6.67 \pm 0.4$ \\
\hline Damaged starch content $(\% d m)$ & $6.78 \pm 0.1$ & $5.22 \pm 0.1$ \\
\hline $\begin{array}{l}\text { Active } \beta \text {-amylase fraction (Units } / g d m^{*} \text { ) } \\
\text { Non-bound }\end{array}$ & $518 \pm 13$ & $499 \pm 35$ \\
\hline
\end{tabular}

* 1 unit = amount of enzyme needed to release one micromole of maltose from soluble starch in one minute at $\mathrm{pH} 6$ and $40^{\circ} \mathrm{C}$ 


\section{Results \\ Comparison of sugar release}

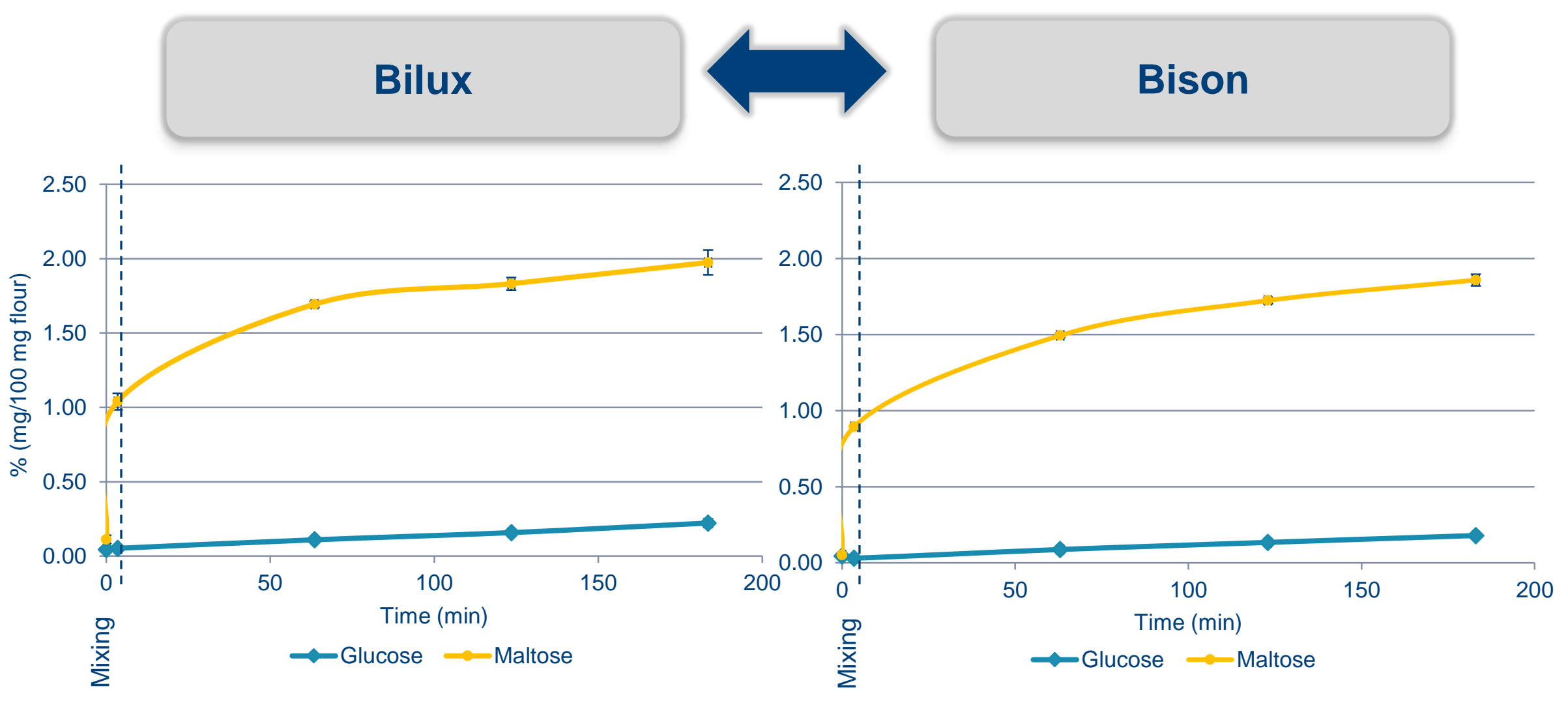

* Release of maltose is not higher in dough prepared from flour with higher $\alpha$-amylase activity

KU LEUVEN 


\section{Results \\ Inhibition and addition of $\alpha$-amylase}

Results of comparion of sugar release in dough samples prepared from Bilux and Bison flour:

a-amylase is not the only limiting factor for sugar release in dough

* Inhibition of $\alpha$-amylase in Bilux flour: $100 \mu \mathrm{mol}$ EDTA/g dm

a-Amylase activity (Amylazyme)

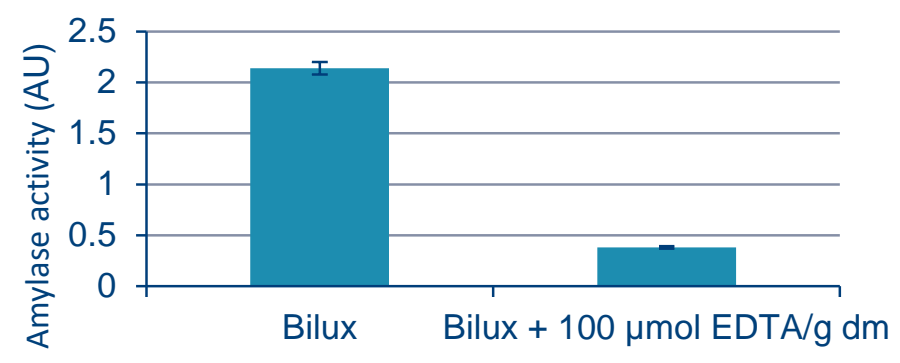

* Addition of $\alpha$-amylase (Aspergillus oryzae; Fungamyl) to Bilux flour

\begin{tabular}{|l|l|l|l|l|}
\hline $\begin{array}{l}\mu \mathrm{L} \alpha \text {-amylase/g } \\
\mathrm{dm}\end{array}$ & 0 & 0.02 & 0.2 & 2 \\
\hline $\begin{array}{l}\text { a-Amylase } \\
\text { activity (AU) }\end{array}$ & 2 & 39 & 235 & 3075 \\
\hline
\end{tabular}

Amylazyme Units $(A U)=\Delta E 590 / g d m . h$

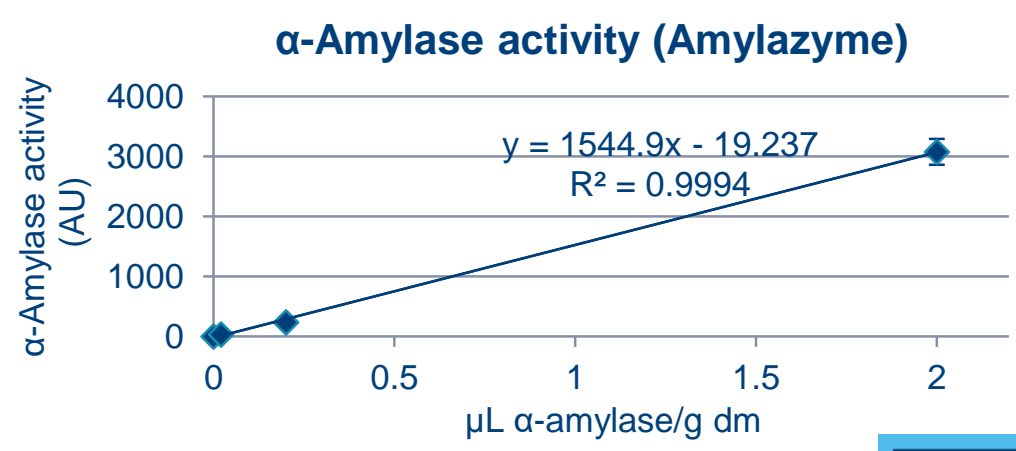




\section{Results}

\section{Sugar release with inhibition of $\alpha$-amylase}

* Addition of $100 \mu \mathrm{mol}$ EDTA/g dm almost completely inactivates $\alpha$-amylase (as indicated by Amylazyme test)

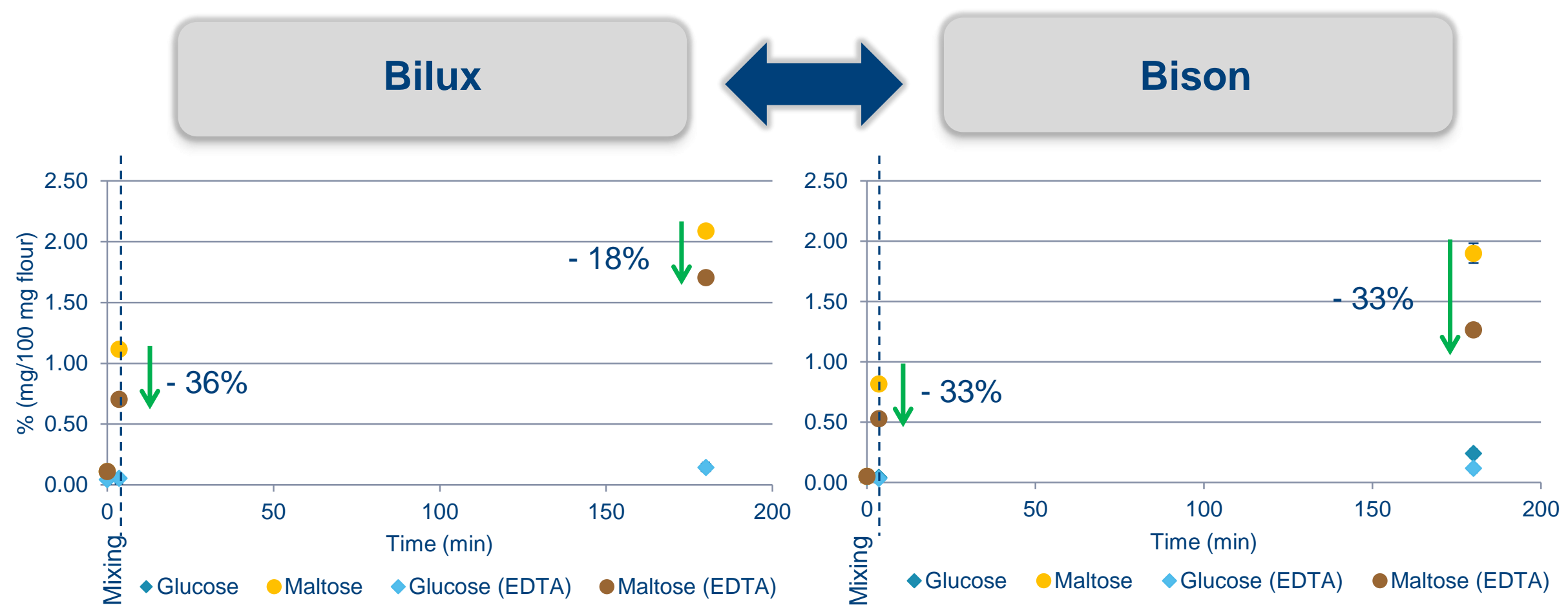

* Release of maltose with inhitibiton of $\alpha$-amylase activity after 180 min is $1.7 \%$ (Bilux) and $1.3 \%$ (Bison) 


\section{Results}

\section{Sugar release with addition of $\alpha$-amylase}

* Addition of varying amounts of a-amylase (Aspergillus oryzae) to Bilux flour to increase the a-amylase activity

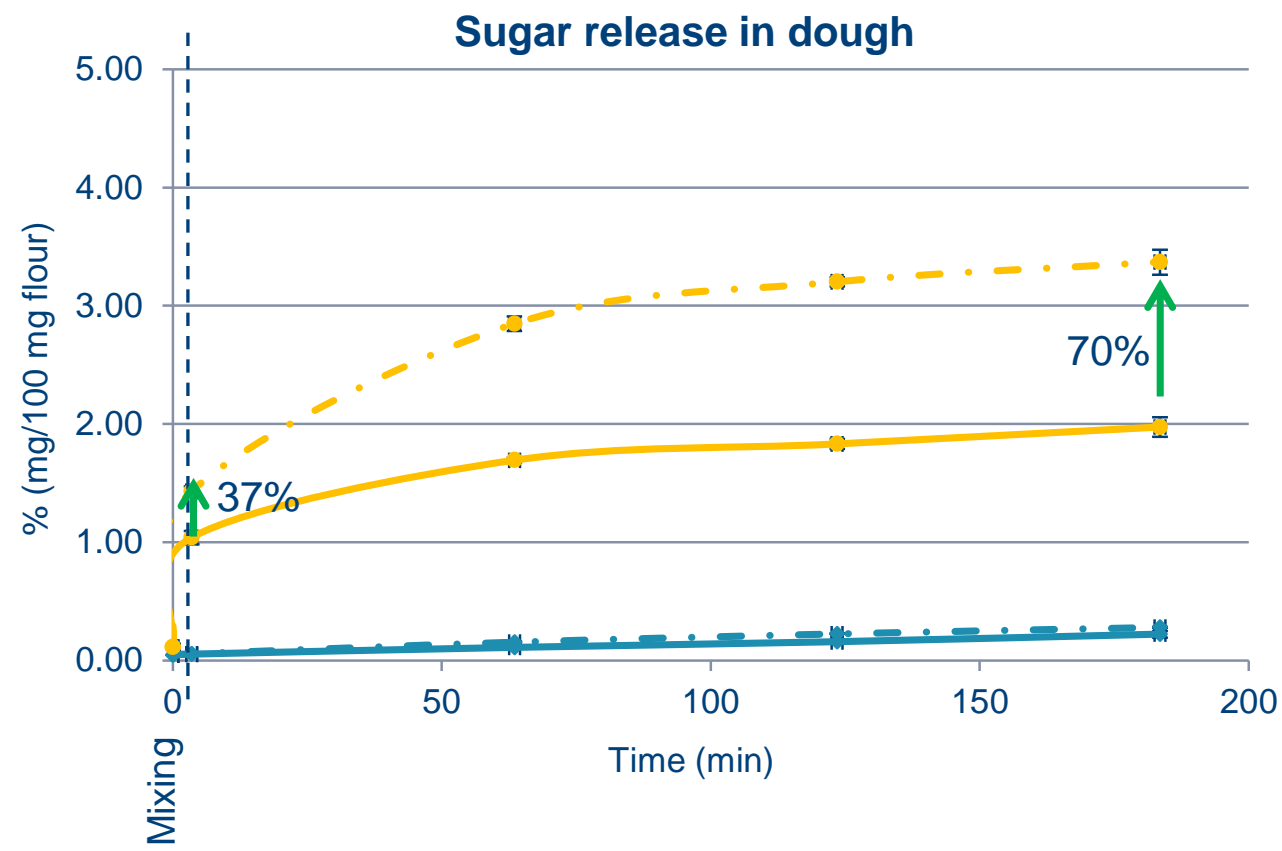

\begin{tabular}{|l|l|l|l|l|}
\hline $\begin{array}{l}\boldsymbol{\mu L} \boldsymbol{\alpha} \text {-amylase } / g \\
\mathrm{dm}\end{array}$ & 0 & 0.02 & & \\
\hline $\begin{array}{l}\text { a-Amylase } \\
\text { activity (AU) }\end{array}$ & 2 & 39 & & \\
\hline
\end{tabular}

$-\cdots \cdot-\cdots-"-0,02 \mu \mathrm{L} \alpha$-amylase $/ \mathrm{g} \mathrm{dm}=39 \mathrm{AU}$ $0 \mu \mathrm{L} \alpha$-amylase $/ \mathrm{g} \mathrm{dm}=2 \mathrm{AU}$ 


\section{Results}

\section{Sugar release with addition of $\alpha$-amylase}

* Addition of varying amounts of a-amylase (Aspergillus oryzae) to Bilux flour to increase the a-amylase activity

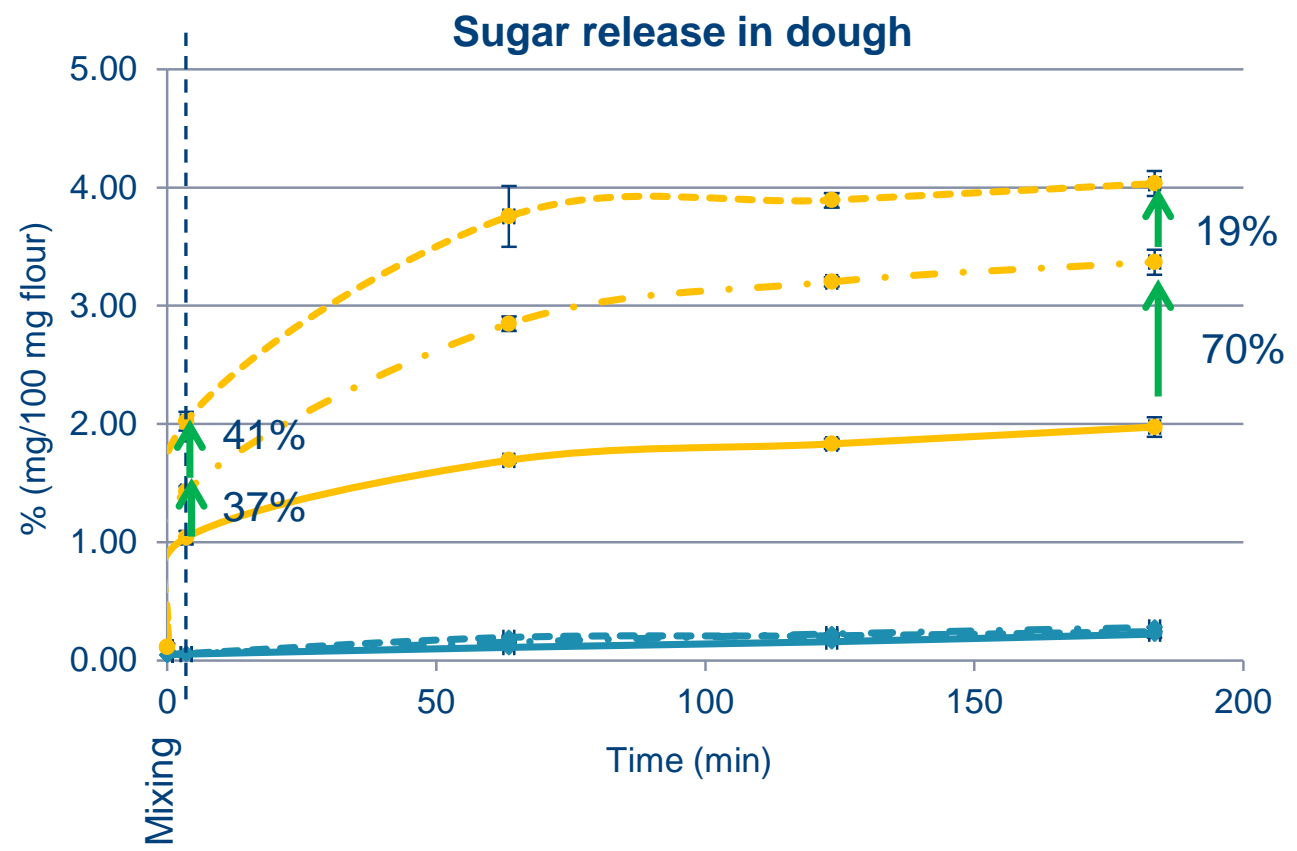

\begin{tabular}{|l|l|l|l|l|}
\hline $\begin{array}{l}\boldsymbol{\mu L} \boldsymbol{\alpha} \text {-amylase } / \mathbf{g} \\
\mathrm{dm}\end{array}$ & 0 & 0.02 & 0.2 & \\
\hline $\begin{array}{l}\text { a-Amylase } \\
\text { activity (AU) }\end{array}$ & 2 & 39 & 235 & \\
\hline
\end{tabular}

$0,2 \mu \mathrm{L} \alpha$-amylase $/ \mathrm{g} \mathrm{dm}=235 \mathrm{AU}$

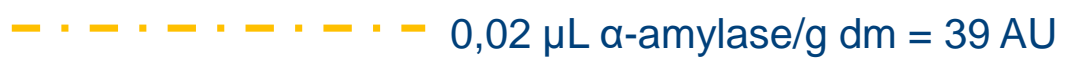

$0 \mu \mathrm{L} \alpha$-amylase $/ \mathrm{g} \mathrm{dm}=2 \mathrm{AU}$ 


\section{Results}

\section{Sugar release with addition of $\beta$-amylase}

Results of comparion of sugar release in dough samples prepared from Bilux and Bison flour:

$\alpha$-amylase is not the only limiting factor for sugar release in dough

* Addition of $\beta$-amylase (Barley) to Bilux flour

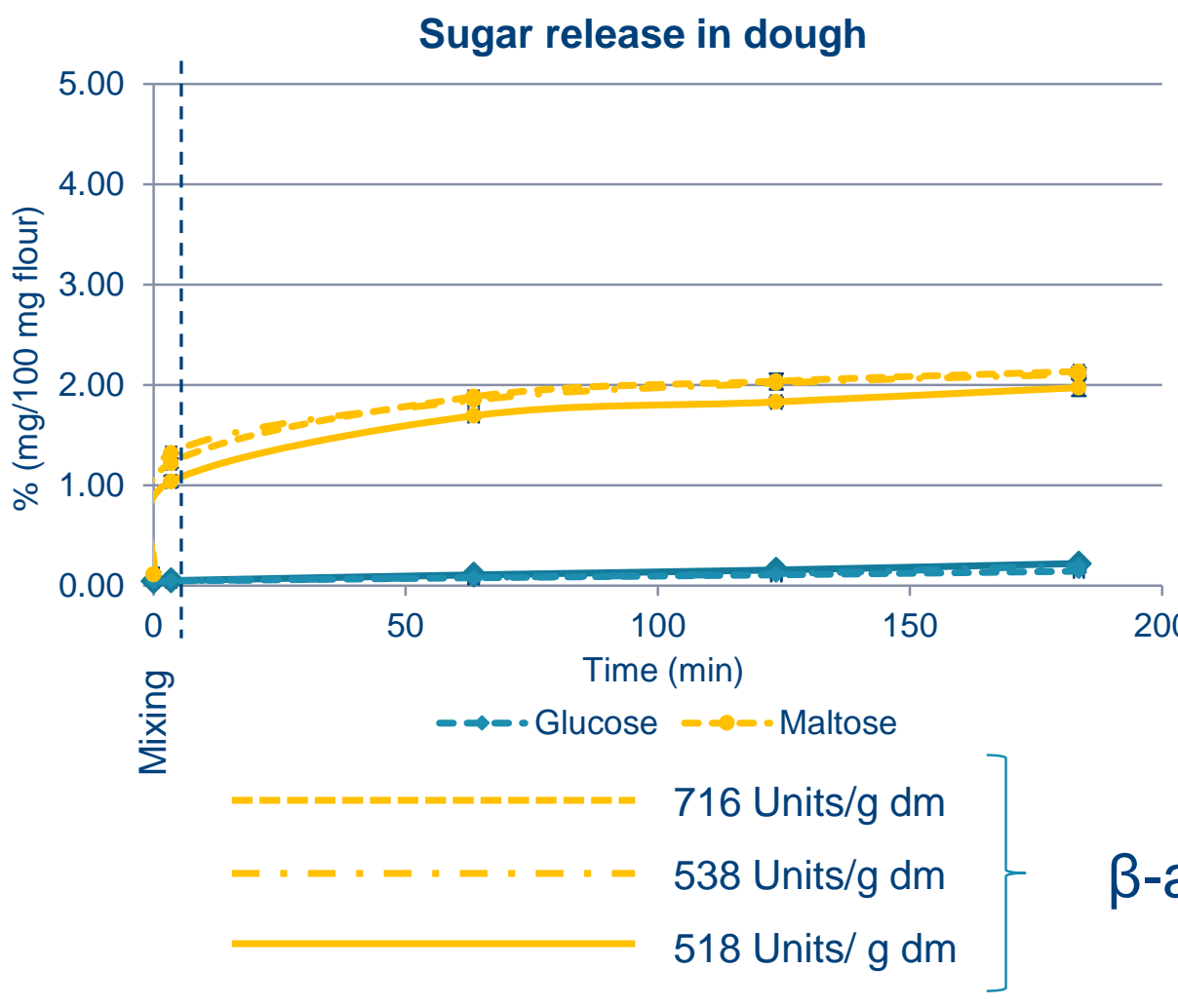

\begin{tabular}{|l|l|l|l|}
\hline $\boldsymbol{\mu L} \boldsymbol{\beta}$-amylase $/ \mathbf{g ~ d m}$ & 0 & 2 & 20 \\
\hline $\begin{array}{c}\beta \text {-amylase activity } \\
(\text { Units } / \mathbf{g ~ d m})\end{array}$ & 518 & 538 & 716 \\
\hline
\end{tabular}

1 Unit = amount of enzyme needed to release one micromole of maltose from soluble starch in one minute at $\mathrm{pH} 6$ and $40^{\circ} \mathrm{C}$

$\beta$-amylase activity 


\section{Conclusion}




\section{Conclusion}

2 different flour types with different amylolytic background

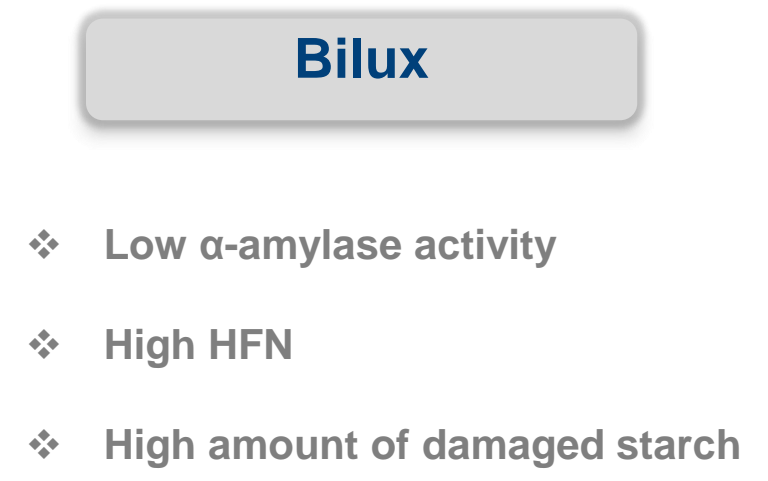

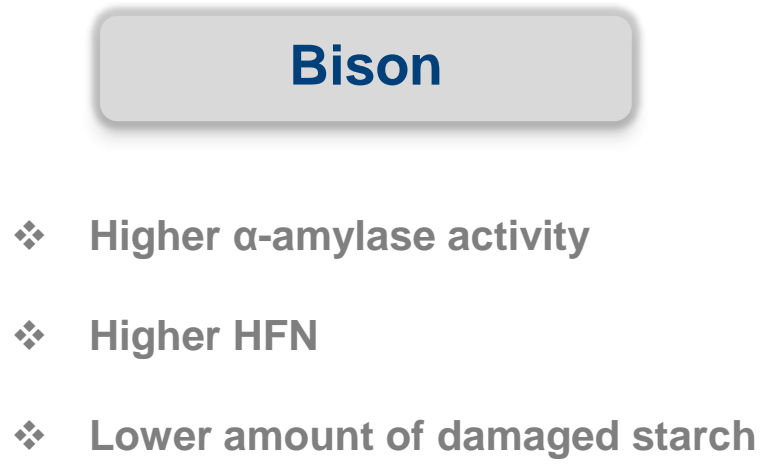

\section{Bison}

Lower amount of damaged starch

$\rightarrow$ Substrate availability is the limiting factor in Bison dough samples, although the damaged starch is not totally degraded (5.2\% starch vs. $1.9 \%$ of maltose released)

$\rightarrow \alpha$-Amylase activity is the limiting factor in Bilux dough samples 


\section{Conclusion}

What are the limiting factors for sugar release in dough?
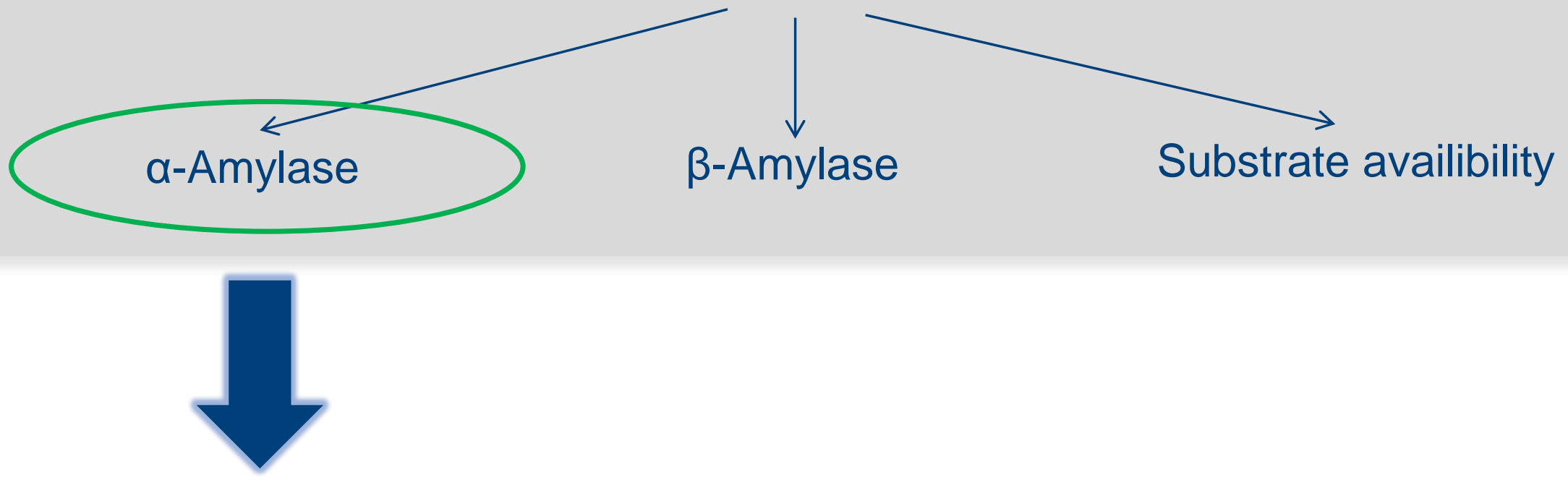

Increasing $\alpha$-amylase activity in dough samples with limited $\alpha$ amylase activity strongly increases the release of maltose 


\section{Conclusion}

What are the limiting factors for sugar release in dough?
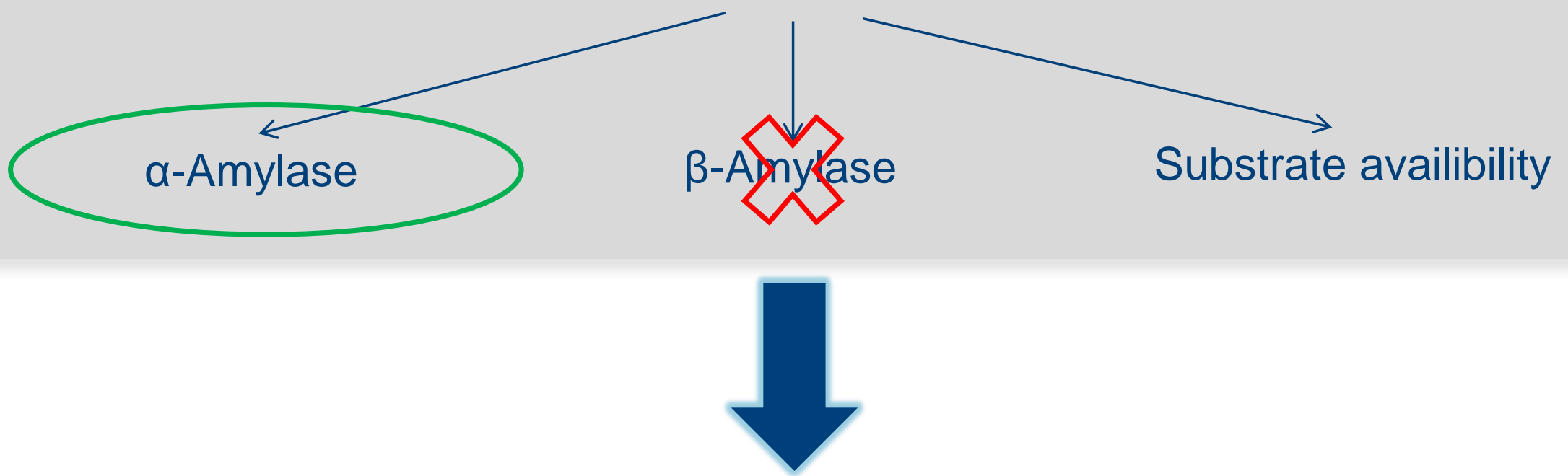

- $\beta$-Amylase activity in wheat flour is not a limiting factor

* $\beta$-Amylase is very important for the release of sugars in dough, since $1.7 \%$ of maltose is released by $\beta$-amylase alone in Bilux dough when $\alpha$-amylase is inhibited 


\section{Conclusion}

What are the limiting factors for sugar release in dough?

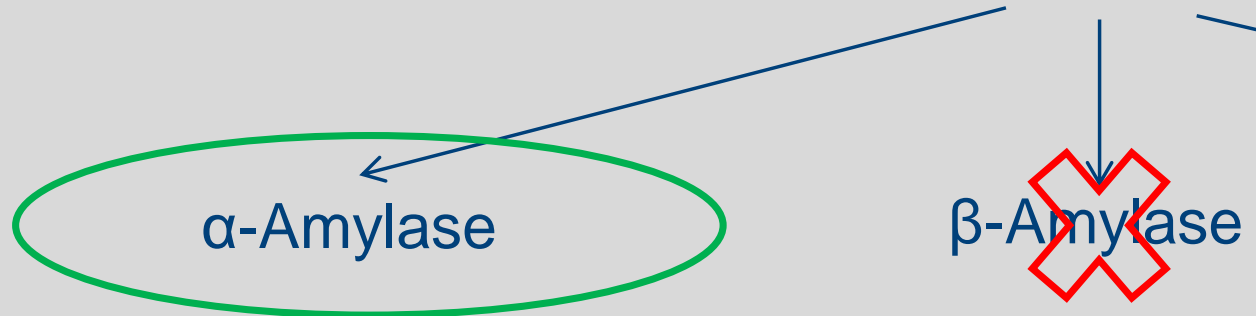

Substrate availibility

Even when $\alpha$-amylase activity is high, sugar release

can be limited by the availibility of damaged starch 


\section{Conclusion}

What are the limiting factors for sugar release in dough?

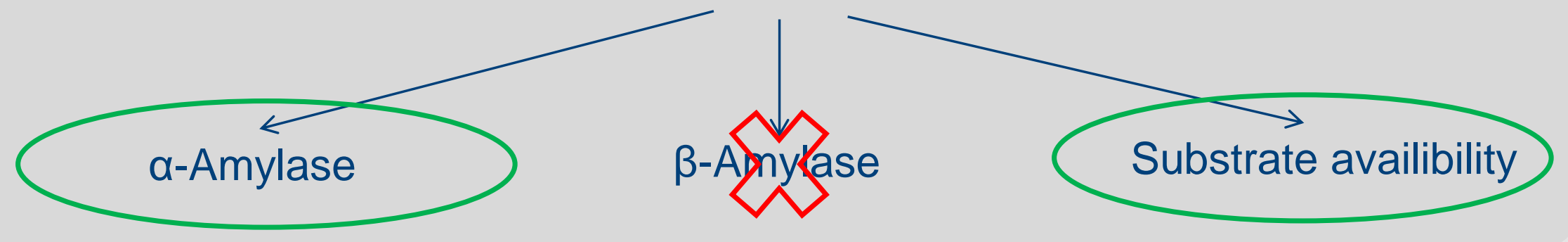




\section{KULEUVEN}

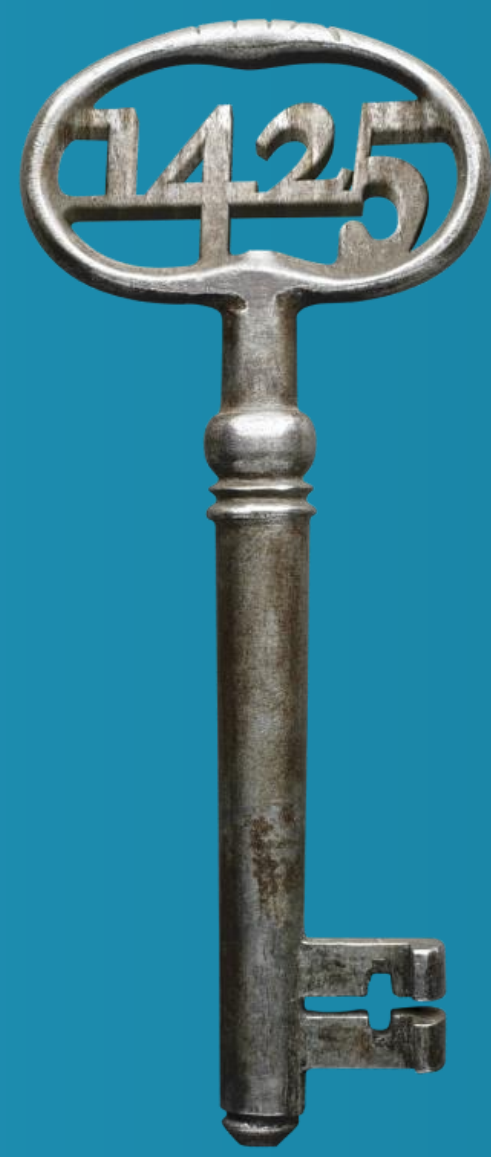

\section{The effect of amylolytic activity and substrate availability on sugar release in non-yeasted dough}

NORE StRuyf, Bianca LefEVERE, KeVIN J. VerstREPEN AND CHRISTOPHE M. COURTIN

14 $4^{\text {th }}$ EYCSTW, Copenhagen, April 162015 